\title{
Method for Economic Assessment of Regulatory Impact (Ria) in Albania. Avdantages and Disadvantages of Economic and Inference Methods
}

\author{
Mimoza Zeneli (PhDCandidate) \\ Ministry of Energy and Industry, Albania \\ mimoza_zeneli@yahoo.com
}

\section{Doi:10.5901/jesr.2014.v4n2p348}

\section{Abstract}

The World Bank in its paper Governance Matters III (2003), refers to the Rule of Law as "the extent to which agents have confidence in and abide by the rules of society." The indicators measured by the World Bank attempt to measure the success of a society in developing an environment in which fair and predictable rules form the basis for economic and social interactions. However, by the early twenty-first century it became clear the importance of the quality of laws and regulations for development. Then, "regulatory quality" started to be considered one of the pillars of good governance by most authors. In the World Bank papers published in 2003 and 2006, six indicators were considered to measure the level of governance of 199 countries: (1) Voice and Accountability; (2) Political Stability and Absence of Violence; (3) Government Effectiveness; (4) Regulatory Quality; (5) Rule of Law and (6) Control of Corruption. Regulatory Impact Assessment (RIA) is a tool which informs decision making in the public sector. It involves an analysis of the benefits, cost and risks of proposed actions by government. By providing information on the likely consequences of introducing a new law, RIA helps improve the effectiveness of government policy. Once the political decision has been taken to pursue a particular objective, RIA can be used to develop alternative policy options and to select the measure that will meet the objective in the most effective and efficient manner. The choice of preferred option will be based on a comparison of the expected positive (benefits) and negative (costs) impacts of each option. Referring above I would like to suggest same economic and inferential method that can be used from Albanian policy maker showing the advantages and disadvantages of using of methods in case of Albania.

Keywords: Impact Assessment, regulatory reform, decision, impact assessment.

\section{The current system of RIA in Albania}

The proposed RIA system for Albania is based on the principle of implementing a 'customised, simple and operational RIA system' that is workable in the current environment and which has the capacity to evolve over time. Albania has an Explanatory Memorandum as an important part of the law drafting process (Law no. 9000, 30 th January 2003). According to the Council of Ministers Decision no.584, 28 ${ }^{\text {th }}$ August 2003, the Explanatory Memorandum should be produced for all regulations and covers the following:

- The aims and objectives of the draft legal act;

- Explanation of how the draft law is related to the country's development strategy and policy objectives;

- Assessment of possible benefits, economic costs and level of effectiveness;

- Problems of enforcement;

- Conformity with existing laws and harmonization with EU legislation;

- Details of persons and institutions consulted and contributing to the drafting process;

- Specification of institutions and/or bodies responsible for enforcing the legal act.

In addition to the Explanatory Memorandum, the draft law should be accompanied by a Budgetary Assessment to include:

- Total amount of annual expenses for implementation of the act;

- Analysis of budgetary expenses for first three years of implementation;

- Where public funds are used, an indication of budgetary allocation.

The existing procedures require a Ministry to submit the draft law (together with the Explanatory Memorandum and Budgetary Assessment) for comment to the Ministry of Justice, the Ministry of Finance and the Ministry of Integration. The draft should also be sent to the Ministry of Economy, Trade and Energy if there is a significant economic content. The draft should also be sent for comment to other Ministries where the draft law is judged to relate to a particular 
Ministry's area of responsibility.

The draft law is revised in the response to the comments received from Ministries and is submitted by the proposing Ministry to the General Secretary of the Council of Ministers (legislative and coordination department). The General Secretary of the Council of Ministers may refer the draft back to the proposing Ministry; before passing it forward to the Inter-ministerial Committee.

The Explanatory Memorandum and the related Budgetary Assessment represent an embryonic Regulatory Impact Assessment. METE, the Council of Ministers and other state organs are convinced that this process offers great potential for evolving into a RIA system. However, this would require modification as well as capacity building in order for it to work effectively, leading ultimately to the creation of more effective policies and legislation.

\section{Monitoring and Evaluation of the Regulatory Reform}

Monitoring and evaluation of Regulatory Reform is intended to identify factors of success or failure of the regulatory management process and to define priority areas for further reform. The exercise participates also in the visibility of the government efforts.

The Systematic monitoring and evaluation of the regulatory reform is included in the long term objectives of the GoA1 and tools to conduct the related activities are already specified.

- Reports prepared by institutions involved in the implementation of the Action plans.

- Business surveys.

- Self-Assessment with the use of the specific tools (filling up of forms by regulators, group meetings, evaluation against the background of best international practices).

The monitoring and evaluation of the regulatory reform was also an individual measure planned in the Action Plan on Regulatory Reform for 2007 but it has been postponed until the BERIS Project provide the necessary support to design the monitoring and evaluation system.

Nevertheless, in the absence of any specific technical support, the DTP at the METE has already demonstrated its capacity to monitor the effectiveness of certain outputs of the Regulatory Reform2. An ad-hoc methodology based on the analysis of samples has been implemented to verify on the spot that recommendations of the Task Force concerning the removal or the simplification of licensing requirements have been duly and uniformly implemented by the responsible public authorities (after the entry into force of the amendments to the relevant regulations on licensing requirements).

Among other monitoring activities of the DTP, worth mentioning also the routinely progress reports on the implementation of the annual Action Plans which are prepared before each meeting of the Task Force on Regulatory Reform.

Furthermore, as a kind of reference to a "peer review", it is clear that priorities of the GoA to deliver results within the Regulatory Reform refer implicitly to the quantitative indicators 3 of the annual IFC/World Bank Doing Business reports4. Further steps to design other indicators to capture broader objectives of the Regulatory Reform do not prevent the continuing use of the Word Bank tests which have the merit to represent the concrete situation of entrepreneurs on the ground and are comparable over time and across various countries.

To some extent, this review produced at the initial stage of the implementation of the BERIS Project with methodological elements drawn on OECD experience may be considered as the first contribution to the monitoring and evaluation system of the Regulatory Reform in Albania. Nevertheless, this contribution based mainly on desk research with limited resources had only modest ambitions. By the end of 2009, the BERIS Project is due to implement a specific activity to design and support the implementation of a monitoring and evaluation system for the Regulatory Reform and the RIA in Albania. Moreover, another assessment of the GoA's Regulatory Reform capacities will be made before the phasing out of the BERIS Project in 2010.

The prerequisite to further refine this methodology (with adjunction of ad-hoc questionnaires) or to adopt another official methodology is contingent on the concept of regulatory quality to be defined by the GoA because the international experience shows that indicators of regulatory quality may vary from one country to another. Those indicators relate to

\footnotetext{
${ }^{1}$ Point 1.3 of the Annex 2 to the Prime Minister Decree No. 157 of 15.03.2006 On "Approval of the Action Plan on the Regulatory Reform to improve business climate".

2 Two monitoring rounds have been carried out.

${ }_{3}^{3}$ Time needed ,administrative and financial costs and number of procedures necessary to comply with certain administrative requirements.

${ }^{4}$ www.doingbusiness.org
} 
policy objectives and the progress expected in building up the administrative capacities to manage regulatory tools such as RIA and consultations with stakeholders.

\section{Economic Valuation Methods and Discounting}

There are three main stages in the application of economic valuation to impacts. The first involves the identification of the potential benefits (positive impacts) and costs (negative impacts). The second stage involves the valuation of the identified costs and benefits in economic terms. Third, since benefits and costs that occur at some time in the future are less valuable than those that accrue in the present, the procedure of discounting is used to convert impacts accruing in different time periods into equivalent values.

\section{Financial Appraisal and Discounting}

In financial appraisal the benefits are given by the revenue receipts from the project outputs and the inputs are given by the costs (expenditures) of production. Market prices are therefore used as the unit of valuation.

The first step in the financial appraisal is to calculate the project's cash flow. This is done by recording on an annual basis the revenues and expenditures for the entire life of the project. The difference between the yearly receipts and expenditures is the net cash flow. Cash received in the future is less valuable than cash received immediately. The reason for this is simply that money received in the future rather than the present represents an opportunity cost, in terms of the income that could have been earned by investing the funds in an interest bearing account or revenue earning productive activity. This is why borrowers have to compensate lenders for the income they are forgoing, by paying a rate of interest. The rate of interest therefore reflects peoples' preference for money in the future; i.e. it represents individuals' 'rate of time preference'.

In order to combine each year's net cash flow into a single aggregate figure, they need to be converted into equivalent terms. This is done by the process of discounting, which converts future values into an equivalent present period value.

\section{Economic Appraisal}

If markets were perfectly competitive, they would produce an economic efficiency outcome, and financial and economic project appraisal would be identical. But we know that perfectly competitive markets seldom, if ever, exist in the real world. The result is that market prices diverge from economic efficiency prices.

There are two main types of market failure which cause market prices to diverge from efficiency prices - imperfect competition and externalities. Most markets are characterized by a degree of imperfect competition. For example, the competitive market may be prevented from emerging by collusion among a small number of major producers preventing other firms from entering the market. Externalities occur when an economic activity has an impact on someone other than the consumer or producer. Environmental damage is one common type of external cost. On the benefit side, training and human capital improvements benefit society as well as the individual.

\section{Economic Valuation Techniques ${ }^{5}$}

There is a range of economic valuation techniques. The choice of technique will depend on the particular impact under consideration and on the availability of data. In some instances, it may be possible to apply several techniques to the valuation of the impact, which can provide a useful cross-check on the reliability of the estimates obtained. Many 'missing' market values occur in the environmental benefits and costs, and the remainder of this annex discusses the use of valuation techniques in relation to environmental impacts.

There are three main ways of calculating economic values: (i) Using market prices; (ii) Using information on individuals' preferences; (iii) Benefit transfer.

Valuation using market prices: Change in productivity: This method values environmental change by observing physical changes in the environment and estimating what difference they will make to the value of marketed goods and services. This approach is applicable in calculating direct and indirect use value. Water pollution can reduce fish catches,

${ }^{5} \mathrm{~A}$ Guide to undertaking Regulatory Impact Assessment and completing the Explanatory Memorandum 
and air pollution can affect the growth of crops. In both instances, the environmental impact reduces marketed output, which may be valued using market prices.

Human capital cost valuation: This method may be used to value the impact of environmental hazards on human health. Environmental 'bads' such as air and water pollution or the use of pesticides reduce the quality of the human capital stock, and therefore lower the economy's productive capacity. To apply the human capital cost method it is first necessary to determine the relation between the hazard and human health, by expressing the health impact in terms of premature death, sickness or absenteeism. Sickness can then be valued using medical and health care costs. Absenteeism is valued in terms of lost earnings (this assumes that earnings measure the contribution that the absent worker would have made to output).

Valuation using information on individuals' preferences:Often it will not be possible to link the environmental impact to a change in marketable output. In these cases, the willingness to pay has to be estimated indirectly, using a range of other techniques, such as:

Replacement cost or preventive expenditure method: The economic value that individuals attach to the environment can sometimes be inferred from the cost of preventing unwanted environmental impacts, or of restoring an asset to its original state after it has been damaged. For example, the costs of air pollution-related acid depositions could be estimated using the costs of restoring damaged physical infrastructure, or the costs of soil erosion could be estimated using the costs of providing preventive terracing.

Contingent valuation method: The contingent valuation method (CVM) relies on direct questioning of people to determine their willingness-to-pay valuation of an environmental impact. A detailed description of the environmental impact is provided, and interviewees are then asked what they would be willing to pay (WTP) for a hypothetical environmental improvement, or to accept (WTA) as compensation for an environmental deterioration. The contingent valuation approach may, in principle at least, capture the total economic value (use and non-use components), whereas other techniques may only provide estimates of direct or indirect use value.

Surrogate market valuation method: Whilst an environmental good or service may not be traded directly, it is sometimes possible to find a good or service, related to the non-marketed environmental item, that is sold in markets. In this situation, the individual may reveal his or her preference for both the market and non-market good or service when making a purchase. It may then be possible to separate-out the environmental component of value from the observed market price, and in this way use this component of market price as a 'surrogate' for the environmental value.

There are two main techniques which have been used for applying the surrogate market method: travel cost method and property value (hedonic price) method. Travel cost method Many natural resources (e.g. a national park or lake) are used for recreational purposes. The travel cost method bases its valuation on the money and time costs of visitors to such recreational facilities.

Property value (or hedonic price) method: The hedonic price method is based on the idea that differences in property prices can be used to infer the value which individuals attach to the difference in environmental quality between properties. For example, the difference in the price of two properties which differ only in, say, the local air quality, will provide a measure of the value which people give to difference in air quality. Even when properties differ in other ways, it may still be possible (though it is a complex task) to uncover the implicit prices of environmental quality using statistical techniques to separate out the contribution of each factor to the total market price.

Benefit transfer. Benefit transfer involves deriving estimates of economic value in one context for use in a different context, where the data required for the estimation are not readily available. For example, the value of health damage from air pollution in one city might be used to estimate health costs from air pollution in a different city or, more controversially, the values derived in one country might be transferred for use in a different country. Though this can provide quick and low-cost estimates, it is subject to a number of limitations.

Refring above the OECD has generalizen in a table the use of different economic methods as below . (OECD , Recent development 2006) 
Figure 6.2. Total economic value

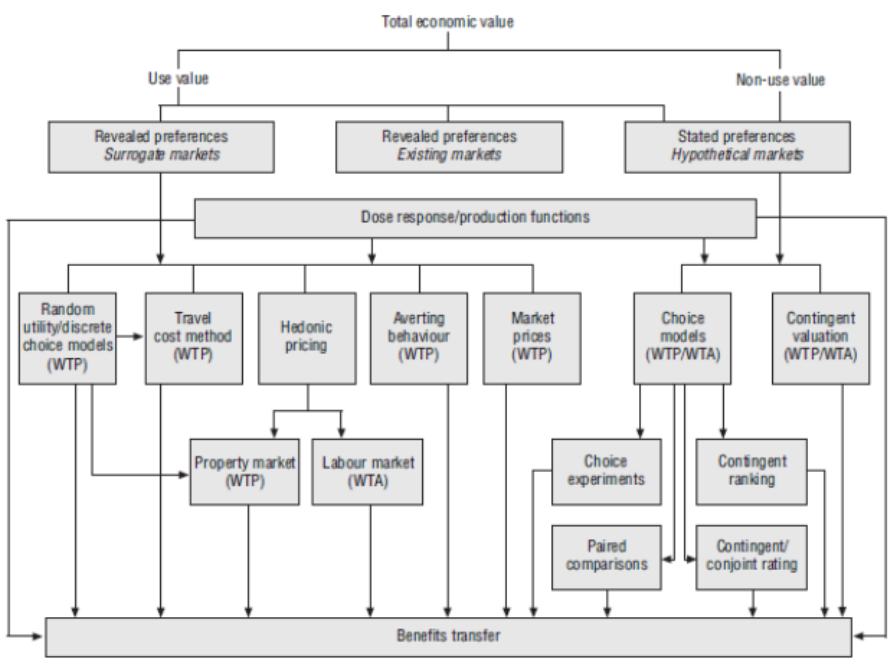

\section{Inferences Methods}

Beside of above mention methods we judged that an alternative method of economic evaluation that can be used is one of inferential method, "Difference to Differences" or "Before and After" methods. This two methods are based on the comparisons of effects of regulation because of regulation implementation.

Differences to Difference methods . Operation of the method is shown in the graph. This method consists in selecting a key variable which is able to express the success of the intervention. ${ }^{6}$ The graph below present an example that tell how the inferencial method operate .

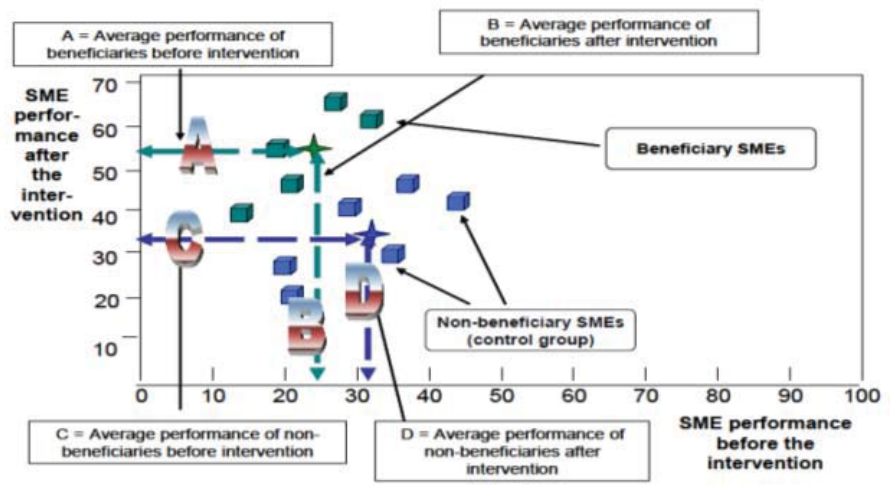

Since the work by Ashenfelter and Card (1985), the use of difference-in-differences methods has become very widespread. The simplest set up is one where outcomes are observed for two groups for two time periods. One of the groups is exposed to a treatment in the second period but not in the first period.

The second group is not exposed to the treatment during either period. In the case where the same units within a group are observed in each time period, the average gain in the second (control) group is substracted from the average gain in the first (treatment) group. This removes biases in second period comparisons between the treatment and control

${ }^{6}$ Evaluation and Impact Assessment of Business Climate Development, Péter Futó Institute of Sociology and Social Policy Corvinus University, Budapest, 2011 
group that could be the result from permanent differences between those groups, as well as biases from comparisons over time in the treatment group that could be the result of trends. Inference based on even moderate sample sizes in each of the four groups is straightforward, and is easily made robust to different group/time period variances in the regression framework. ${ }^{7}$ With repeated cross sections, we can write the model for a generic member of any of groups as

$$
Y=\beta_{0}+\beta_{1} d B+\delta_{0} d 2+\delta_{1} d 2 * d B+u
$$

where $y$ is the outcome of interest, $d 2$ is a dummy variable for the second time period. The dummy variable $d B$ captures possible differences between the treatment and control groups prior to the policy change. The time period dummy, $d 2$, captures aggregate factors that would cause changes in $y$ even in the absense of a policy change. The coefficient of interest, $\delta_{1}$ multiplies the interaction term, $d 2 \cdot d B$, which is the same as a dummy variable equal to one for those observations in the treatment group in the second period. The difference-in-differences estimate is

$$
\hat{\delta}_{1}=\left(\bar{y}_{B, 2},-\bar{y}_{B, 1}\right)-\left(\bar{y}_{A, 2},-\bar{y}_{A, 1}\right)^{8}
$$

Inference based on even moderate sample sizes in each of the four groups is straightforward, and is easily made robust to different group/time period variances in the regression framework. In some cases a more convincing analysis of a policy change is available by further refining the definition of treatment and control groups.

Based on above, conclude that there are a lot of methods for economic and impact evaluation of regulatory reforms. The question stands Albania Capacity are prepared for using the different methods of assessing the impact of regulatory reform...... ??

\section{Conclusion and Recommendation}

RIA now is a problem to be solved that ask for all elements of government to improve the way that ensure regulatory efficiency, effective protection for citizens and reduced opportunities for corruptions.

Experience of regulatory reform in OECD countries indicates however that economic performance in the international competitive environment call for broader objectives of good governance to change the administrative culture towards the transition from "state-led to market-led" economic growth

Improving the quality of regulatory decision making is the core of Albanian development. By insuring a method for improving the quality of regulatory decision making, RIA can assist policymakers in addressing regulatory needs in Albania.

Taking into account the existing capacity constraints in the Albanian public administration, the immediate launch of a comprehensive system of RIA launch of an RIA light system is more favourable for Albania conditions as actually happened in Albania.

Based above we recommends setting up a centre for economic and social research for gathering and analysing dates for most important fields in interest of decisions makers. This centre will be the fundamental rink that will help decisions- maker with quality and coherence informacion and analyses.

It was said in substance that South East European Countries have no other choice than to accelerate regulatory reforms beyond the stage of simplification of regulation, because the international context is changing rapidly and other regions in the world are competing vigorously

\section{Reference}

OECD (2005), OECD Guiding Principles for Regulatory Quality and Performance.

OECD (2007) Stéphane Jacobzone, Chang-Won Choi, and Claire Miguet, "Indicators of Regulatory Management Systems", OECD Working Papers on Public Governance, No. 4.

OECD (1997), The OECD Report on Regulatory Reform: Synthesis.

Regulatory Governance in South East European Countries - Progress and Challenge, Regulatory Governance Initiative of the Investment Compact, OECD 2004.

OECD (2004) Regulatory Performance: Ex-Post Evaluation of Regulatory Tools and Institutions. Draft report by the Secretariat GOV/PGC/REG(2004)6,15 October 2004.

Review of regulatory reform capacity of the government of Albania , (Final raport)

OECD (2005), OECD Reviews of Regulatory Reform, Regulatory Reform in Russia, Government Capacity to Assure High Quality Regulation.

\footnotetext{
7 Imbens/Wooldridge, Lecture Notes 10, Summer '07

8 Imbens/Wooldridge, Lecture Notes 10, Summer '07
} 
OECD Reviews of Regulatory Reform - Background Document on Regulatory Reform in OECD Countries.

OECD, Measuring Regulatory Quality. Policy Brief, April 2008.

Panorama of options for the design and the introduction of a ria system in Albania international best practice and lessons learnt from the functioning of ria programs abroad, (draft raport)

OECD (1995). Recommendation of the Council of the OECD on Improving the Quality of Government Regulation. OCDE/GD(95)95

Administrative Simplification. Best Practices in OECD Countries. Expert Seminar OECD Headquarters, Paris, 18-19 October 2001.

SME Policy Index 2007. Report on the Implementation of the European Charter for Small Enterprises in the Western Balkans prepared by the European Commission Directorate General for Enterprise and Industry and the OECD Investment Compact for South East Europe (OECD 2007, EC 2007).

SIGMA Paper No. 42. Regulatory Management Capacities of Member States of the European Union that joined the Union on 1 May 2004 - GOVISIGMA(2007), 6 June 2007.

OECD (2008). Building an Institutional Framework for Regulatory Impact Analysis (RIA): Guidance for Policy Makers. Version 1.1.

OECD (2004). Regulatory Impact Analysis (RIA) Inventory. Note by the Secretariat GOV/PGC/RD(2004)1, 15 April 2004.

Regulatory Impact Analysis in OECD Countries, Challenges for developing countries (South Asian-Third High Level Investment Roundtable, Dhaka, Bangladesh, June 2005).

World Development Report 2005, http://siteresources.worldbank.org/INTWDR2005/Resources/07_WDR_Ch 05. Pdf

The 1995 Recommendation of the Council of the OECD on Improving the Quality of Government Regulation

Gamser et al (2002). Indigenous Private Sector Development and Regulation in Africa and Central Europe: A 10 Country Study (Bannock Consulting)

Imbens/Wooldridge ( Summer 2007), Lecture Notes 10. 